\title{
Globe
}

Revue internationale d'études québécoises

\section{Micheline Tremblay et Guy Gaudreau [éd.] : Conversation poétique. Correspondance littéraire entre Harry Bernard et Alfred DesRochers, Ottawa, Éditions David, 2005}

\section{Michel Lacroix}

Volume 10, numéro 1, 2007

URI : https://id.erudit.org/iderudit/1000123ar

DOI : https://doi.org/10.7202/1000123ar

Aller au sommaire du numéro

Éditeur(s)

Globe, Revue internationale d'études québécoises

ISSN

1481-5869 (imprimé)

1923-8231 (numérique)

Découvrir la revue

Citer ce compte rendu

Lacroix, M. (2007). Compte rendu de [Micheline Tremblay et Guy Gaudreau [éd.] : Conversation poétique. Correspondance littéraire entre Harry Bernard et Alfred DesRochers, Ottawa, Éditions David, 2005]. Globe, 10(1), 195-196.

https://doi.org/10.7202/1000123ar d'utilisation que vous pouvez consulter en ligne.

https://apropos.erudit.org/fr/usagers/politique-dutilisation/ 
amène à une conclusion qui détonne par rapport aux autres textes: parlant de Miron, elle affirme que " [d]ire l'absence de l'autre comme la nonprésence à soi, c'est affirmer une liberté individuelle et élargir le champ des possibles, par l'effort de clarification des perceptions et le courage que suppose un tel acte" (p. 131). Ces notions de "liberté", de "clarification" et de "courage" semblent éviter les équivoques temporelles chez Miron, ainsi qu'une certaine pensée du politique.

Les différents textes rassemblés dans $A u$-delà de L'homme rapaillé: Poèmes épars constituent un état partiel de la critique mironienne actuelle et une stimulante mise à l'épreuve des lectures canoniques de L'homme rapaillé, particulièrement dans ses rapports complexes au politique et au temps. Cependant, ces premiers regards sur l'archive ont en majeure partie eu tendance à situer l'archive bel et bien "au-delà" de l'œuvre, ce qui explique le peu de cas fait des poèmes anciens qui font également partie de Poèmes épars. On regrette donc qu'une lecture génétique n'y ait pas trouvé place, ce qui aurait ouvert un peu plus l'atelier du poète et permis d'aborder l'archive d'une tout autre manière.

Manon Plante

Université de Montréal

\section{Micheline Tremblay et Guy Gaudreau [éd.] Conversation poétique. Correspondance littéraire entre Harry Bernard et Alfred DesRochers \\ Ottawa, Éditions David, 2005.}

Sous un titre banal et quelque peu trompeur - tout n'est pas centré sur la poésie dans les lettres en question, ni hanté par le ton poétique -, le lecteur est plongé dans ces années qui, vers 1930, virent une nouvelle génération d'écrivains entrer, en ordre dispersé, sur la scène littéraire, pour y renouveler la poésie et le roman, avant de la quitter prématurément pour sombrer dans l'oubli. Seul DesRochers, de leur lot, a évité ce sort. L'intérêt historique de ces lettres, nombreuses et étoffées, est donc vif, et la "voix épistolaire" de DesRochers, vive, espiègle et volontiers envenimée, y ajoute le plaisir du texte, au point de porter ombrage à celle de Bernard, plus posée, sans être empesée. Les annotations, abondantes et bien informées, de pair avec la présentation soignée, témoignent d'un travail 
solide. Souhaitons que d'autres chercheurs et éditeurs suivent cet exemple: malgré le foisonnement d'études sur l'épistolaire, les sociabilités et les réseaux, bien peu des correspondances dues aux écrivains ont eu droit à la publication. Un bémol, cependant : ici et là, les notes laissent paraître quelque parti pris, ainsi quand on juge «dommage qu'il [Bernard] [...] mêle la morale à la poésien. On est alors tenté de dire, à notre tour: dommage que le jugement se mêle au commentaire.

Michel Lacroix

Université du Québec à Trois-Rivières 